Article

\title{
Strain Rate Effect on the Ductile Brittle Transition in Grinding Hot Pressed SiC Ceramics
}

\author{
Pai Huang ${ }^{1}$ and Jiaqi Zhang ${ }^{1,2, *}$ \\ 1 Key Laboratory of Automobile Materials, Ministry of Education, College of Materials Science \\ and Engineering, Jilin University, Changchun 130012, China; ph7771@outlook.com \\ 2 School of Chemistry and Environmental Engineering, Changchun University of Science and Technology, \\ Changchun 130013, China \\ * Correspondence: zhangjiaqi@jlu.edu.cn
}

Received: 19 April 2020; Accepted: 19 May 2020; Published: 27 May 2020

check for updates

\begin{abstract}
Surface and subsurface damage are still persistent technical challenges for the abrasive machining hot pressed-silicon carbide (HP-SiC) ceramics. Therefore, an investigation of the material behavior and critical depth of ductile to brittle transition (DBT) is essential for improving high precision and quality grinding HP-SiC ceramics. In this paper, single-grit grinding experiments with different scratch speed were conducted to study strain rate effect on the critical depth of DBT. The nanoindentations were performed to test the hardness and Young's modulus changes of DBT position under different scratch speeds. The material removal mechanism and phase changes underneath the scratch groove were investigated using Raman tests. Based on the specific energies consumed in ductile and brittle modes of machining, a theoretical model of the critical depth of DBT was developed. The experimental results suggest that high scratch speeds generate high nanohardness, high Young's modulus and high critical depth of DBT of HP-SiC ceramics. The measured critical depth of DBT shows a good agreement with the predicted value calculated by the developed model. The subsurface damage depth reduced with high strain rate. Furthermore, the Raman results revealed that dislocations and amorphous transformation dominated the ductile removal mechanism of HP-SiC grinding. The fracture chips and subsurface damage depth was determined by the lateral crack and median crack, respectively. This paper's results provide a fundamental understanding of the effect of grinding speed on the material removal mode of HP-SiC ceramics.
\end{abstract}

Keywords: strain rate; single-grit grinding; ductile to brittle; dislocations; amorphous

\section{Introduction}

Due to high specific stiffness, high chemical inertness, high thermal conductivity and enhanced radiation stability, silicon carbide $(\mathrm{SiC})$ is emerging as a prime candidate for several engineering applications, which are common in combustion environments, military-grade vehicle control sensing and space exploration [1-4]. However, as a typical hard and brittleness material, hot pressed (HP)-SiC is difficult to machine as it always generating surface defects and considerable subsurface damage during processing, which affects the lifetime of components. High quality products of ceramics free of cracks can be achieved by ductile regime machining. Generally, grinding is considered to be the most effective surface finish process for obtaining a surface of high integrity and high-dimensional accuracy for ceramics $[5,6]$. However, the grinding process involves a complex behavior of interaction between mass random grains that are distributed on the wheel and workpiece surface. Such cases that lead to the exploration of machining deformation and removal mechanisms are difficult.

Therefore, numerous researchers adopted scratch tests in terms of experiments and simulation methods which could compare to the grinding process in order to study the removal behavior of 
ceramics. Cao et al. [7] found the cutting ability of the tool was significantly improved by the assistance of ultrasonic when comparing the results of scratch tests with and ultrasonic assistance. Furthermore, they put forward that the critical depth of cut for the ductile to brittle transition is increased by $56.25 \%$ with ultrasonic assistance. Similarly, Zhu et al. [8] revealed that SiC was dominated by the ductile removal mode when maximum undeformed chip thickness was below $0.29 \mu \mathrm{m}$ in single-grit simulation. The microstructure effect of $\alpha$-SiAlON was also explored using scratch tests [9]. They found the fine equiaxed microstructure exhibited high resistance to material removal at low loads. Ghatu and Raka [10] claimed that the scratch process-induced damage is closely related to the inherent porosity and the initial microstructure of ceramics. Furthermore, there are some studies that have addressed the deformation mechanism of $\mathrm{SiC}$ ceramics. The propagation and interaction between cracks are the main types responsible for material peeling, and scratch depth and separation of adjacent scratches dictate the interaction of cracks [11]. Meng et al. [12] and Li et al. [13,14] reveled that phase transformation and dislocation movement dominate the ductile removal of $6 \mathrm{H}-\mathrm{SiC}$ and reaction-bonded $\mathrm{SiC}$ ceramics by completing a Transmission Electron Microscopy (TEM) test of the subsurface damaged by scratches. In the molecular dynamic (MD) simulation, Xiao et al. [15] point out that Frank partial dislocations and basal plane edge dislocations are the primary mechanism for the ductile deformation of $6 \mathrm{H}-\mathrm{SiC}$. While some fundamental understanding has been investigated, previous studies rarely considered the effect of strain rate caused by grinding speed on the critical depth of DBT. In addition, structure characterizes HP-SiCs including 3C, $4 \mathrm{H}$ and $6 \mathrm{H}$ crystal, and the way in which sinter-additives lead the relationship between material removal behavior and mechanism is complicated and not clear.

In this study, single-grit scratch tests were used to elucidate the strain rate effect on the DBT of HP-SiC. A comprehensive scanning electron microscope (SEM) observation for scratch topography and Raman analysis of the removal mechanism were completed to explain the strain rate effect on the DBT of HP-SiC ceramics. The hardness and Young's modulus of DBT position were measured by nanoindentation. A theoretical model was developed based on the specific cutting energies consumed in ductile and brittle modes taking the scratch speed into consideration. The results will provide a more practical investigation for the ductile machining of HP-SiC, which helps to minimize and avoid the induced damages in machining processes.

\section{Materials and Methods}

The HP-SiC ceramic samples with dimensions of $10 \times 10 \times 5 \mathrm{~mm}$ used in the scratch experiments were supplied by the College of Materials Science and Engineering at Jilin University. The physical properties are listed in Table 1. To minimize surface damage effect, polishing was completed on both sides of the workpiece until the average surface roughness Sa was $5 \mathrm{~nm}$, as shown in Figure 1 . It can be found that $\mathrm{SiC}$ particles randomly distribute with different orientation, and residual carbides disperse at grain boundary. Scratch tests were performed on a three axis ultra-precision diamond turning machines. A Berkovich indenter was fixed on the aerostatic spindle by a holder with edge-forward orientation. The scratch behavior with different speeds was driven by the spindle rotation. This type of process of varied scratch depths which change from shallow to deep and finally back to shallow can ensure that the material undergoes the ductile to brittle deformation. The SiC workpiece was installed on a Kistler dynamometer (9129AA, Kislter, Winterthur, Switzerland) which is mounted on an aerostatic bearing slide. The displacement of the indenter was recorded by the displacement sensor. The procedure of the scratching experiment is illustrated in Figure 2. 


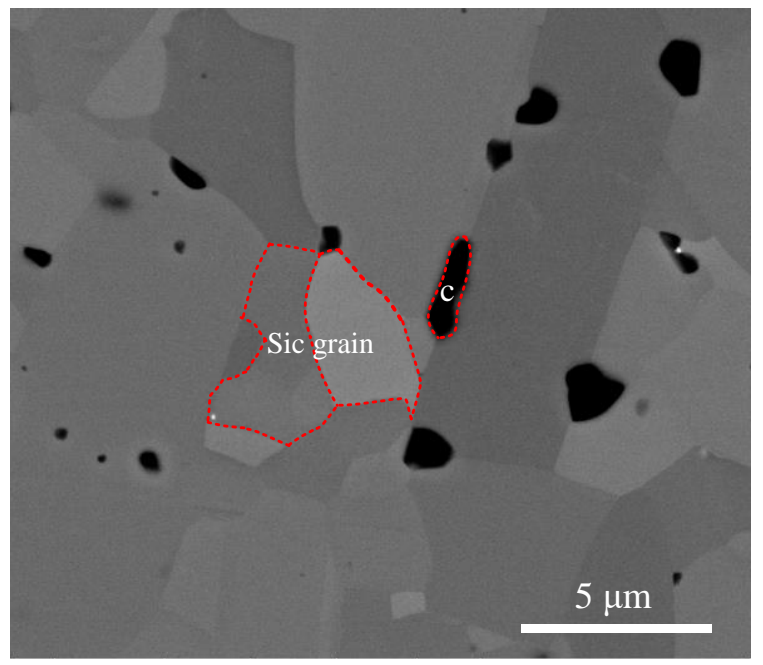

Figure 1. Surface topography of polished HP-SiC ceramics.

Table 1. Physical properties of HP-SiC.

\begin{tabular}{cc}
\hline Properties & HP-SiC \\
\hline Elastic modulus E $(\mathrm{GPa})$ & 400 \\
Vickers hardness $\mathrm{H}\left(\mathrm{kg} / \mathrm{mm}^{-2}\right)$ & $2400-2800$ \\
Shear strength $(\mathrm{MPa})$ & $210-380$ \\
Tensile strength $(\mathrm{MPa})$ & 400 \\
Compressive strength $(\mathrm{MPa})$ & $1000-1700$ \\
Fracture toughness $\mathrm{KIC}\left(\mathrm{MPa} \cdot \mathrm{m}^{1 / 2}\right)$ & $4.0-5.0$ \\
Density $\varrho\left(\mathrm{g} / \mathrm{cm}^{3}\right)$ & 3.15 \\
Passion ratio $v$ & 0.17 \\
\hline
\end{tabular}

To gain insight on the removal behavior corresponding to the different stain rate, the scratch speeds were chosen as $0.01 \mathrm{~m} / \mathrm{s}, 0.3 \mathrm{~m} / \mathrm{s}, 1 \mathrm{~m} / \mathrm{s}$ and $2 \mathrm{~m} / \mathrm{s}$. The distance between each scratch trajectory was set to $2 \mathrm{~mm}$ to avoid the interference. In addition, to gain statistically reliable data, each scratch parameter was repeated five times and the averages were taken as the final values. All tests were carried out at room temperature. After scratch experiments, the topography of the scratch grooves were observed by SEM (Helios Nanolab 600i, FEI, Hillsboro, OR, USA). Raman spectrum were collected from chips with ductile and fracture types to uncover the deformation and fracture patterns. The critical depth of DBT was measured by atomic force microscopes (AFM). Afterwards, the nanoindentation experiments were performed at $50 \mathrm{mN}$ loading using the MTS NanoXP Nanoindenter system (MTS Cooperation, Nano Instruments, Eden Prairie, MN, USA). The indenter tip is also a Berkovich indenter with a tip radius of about $60 \mathrm{~nm}$. Thus, the nanohardness $(\mathrm{H})$ and Young's modulus (E) measures were deliberately made at the vicinity of, inside, and across the scratch grooves at the DBT position with z $10 \mu \mathrm{m}$ interval. The loading and unloading times were held constant at 10 seconds. Finally, the corresponding cross sectional was polished by focused ion beam (FIB) in situ etching (Helios Nanolab 600i, FEI) and investigated by SEM. 


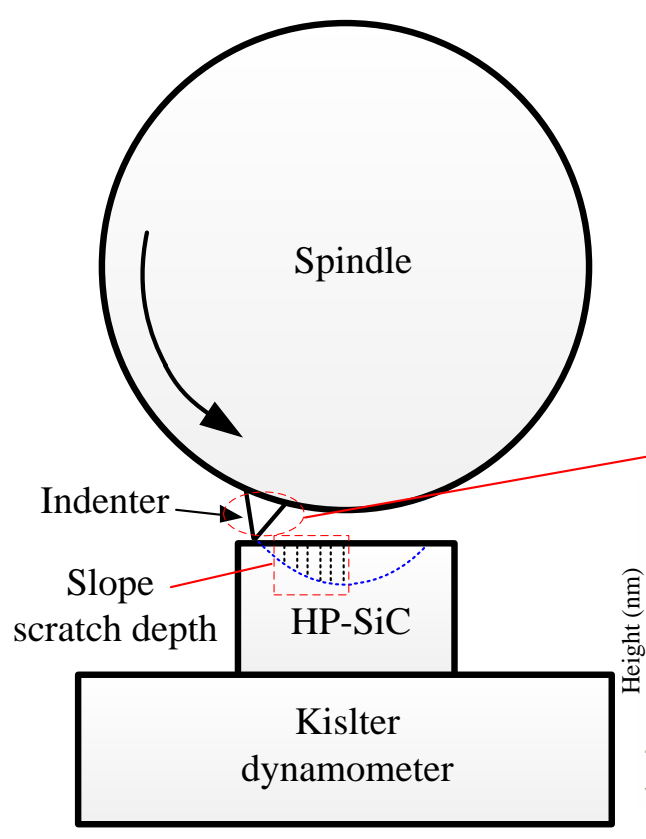

(a) The schematic diagram of scratch test

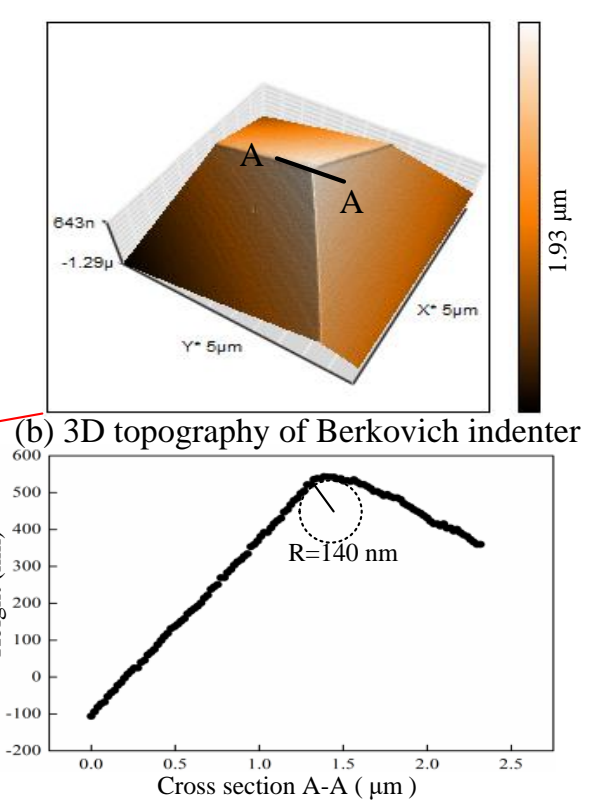

(c) The cross section profile of A-A

Figure 2. (a) The schematic diagram of scratch test; (b) 3D image of the Berkovich indenter and (c) cross-section profile of A-A.

\section{Modelling of DBT}

\subsection{Specific Cutting Energy in the Ductile Regime}

In the plastic deformation stage, the energy consumption is equal to the product of tangential force and tangential velocity. The total tangential force can be divided into three parts, namely, friction force $F_{t f}$, tangential cutting chip formation force $F_{t c}$ and elastic restoring force $F_{e t}$ at the rake face and flank face of the indenter, respectively.

$$
F_{\text {total }}=F_{t c}+F_{t f}+F_{e t}
$$

A previous study [16] revealed that the scratch normal load $F$ can be expressed by the horizontally projected area of the contact area between the indenter and sample $A_{T}$ :

$$
F=P_{m} \cdot A_{T}
$$

where $P_{m}$ is a contact stress that is always simplified to an average pressure $\sigma_{y}$. In this paper, it is considered to be equal to the yield strength of HP-SiC ceramics. The yielding of a crystal is a thermally activated process and the yield stress $\sigma_{\mathrm{y}}$ can be expressed by an exponential function of the strain rate $\dot{\varepsilon}$ [17]:

$$
\sigma_{y}=A \dot{\varepsilon}^{1 / n} \exp \left(\Delta H_{\tau} / k_{B} T\right)
$$

where $A$ and $n$ are constants, and $\Delta H_{\tau}$ such that $n \Delta H_{\tau}$ is an energy parameter for the activation of energy for dislocation glide $\Delta H_{d}$ (see, e.g., [18]). $T$ is the temperature of loading that equals room temperature. The strain rate $\dot{\varepsilon}$ is the time derivative of strain, which describe the deformation velocity of the material during the scratch process. It can be expressed as follows [19]:

$$
\dot{\varepsilon}=\frac{v_{s}}{d}
$$


Furthermore, the tangential force in the ductile regime can be obtained by substituting Equation (3) and Equation (4) into Equation (2):

$$
\begin{gathered}
F_{t c}=\sigma_{y} \cdot A_{T} \\
F_{t f}=\mu F_{N}=\mu \sigma_{y} \cdot A_{N} \\
F_{t e}=\sigma_{y} \cdot A_{N e}
\end{gathered}
$$

where $A_{T}$ and $A_{N}$ are the projection area of the Berkovich indenter in contact with material in the vertical direction. As shown in Figure 3, the projection area can be divided into three parts based on scratch depth $d$, namely the sphere section when $0<d \leq d_{2}$, the intermediate transition section when $d_{2}$ $<d \leq d_{1}$ and the triangular pyramid section when $d \geq d_{1}$. According to the geometric of Berkovich, $d_{1}$ and $d_{2}$ can be expressed as follows:

$$
\begin{gathered}
d_{1}=R(1-\sin \alpha) \\
h^{*}=R(1 / \sin \alpha-1) \\
d_{2} \cdot\left(d_{2}-2 R+\tan \theta\right)=\tan \theta \cdot R \cdot(1-\sin \alpha)
\end{gathered}
$$

where $\alpha$ is the centerline of the ridge equal to $77^{\circ}$ and $\theta$ is the centerline of the face equal to $65.3^{\circ} \cdot d_{1}{ }^{\prime} \mathrm{s}$ calculated value is $3.58 \mathrm{~nm}$ base on the tip radius of the indenter measured in Section 2. In this paper, both the critical DBT depth and scratch depth are large than $d_{1}$. Therefore, only the third parts should be considered. The project area of $A_{N}, A_{T}$ and $A_{N e}$ can be obtained by:

$$
\begin{gathered}
A_{N}=\sqrt{3} / 2 \cdot\left(d+d_{1}\right) \cdot \tan ^{2} \beta \cdot\left(d+d_{1}+d_{e}\right) \\
A_{T}=\sqrt{3} \cdot\left(d-d_{e}\right) \cdot\left(d+d_{e}+2 d_{1}\right) \cdot \sin \theta / \cos ^{2} \theta \\
A_{N e}=3 \sqrt{3} \cdot\left(d_{e}+d_{1}\right) \cdot d_{e} \cdot \sin ^{2} \theta / \cos \theta
\end{gathered}
$$

where $d_{e}$ is depth caused by elastic recovery.
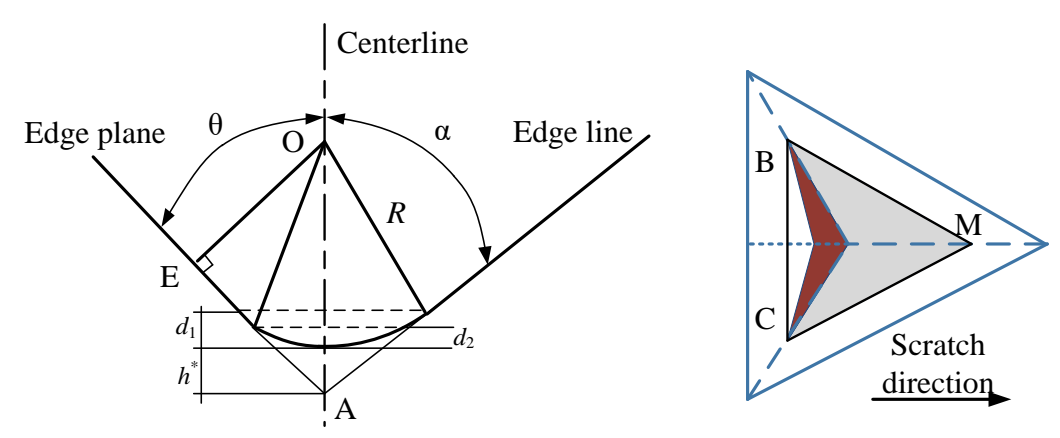

Figure 3. The dimension of the Berkovich indenter and projection area with an edge-forward scratch.

According to the reference, the elastic recovery depth can be given by the function of material hardness, elastic modulus $E$ and tool geometry [20]:

$$
d_{e}=\lambda R H_{s} / E
$$

where $H_{S}$ is the scratch hardness, which can be expressed by [18]:

$$
H_{s}=c\left(v_{s} / d\right)^{m}
$$


where $c$ and $m$ are constant, $v_{\mathrm{S}}$ is the scratch velocity and $d$ is the scratch groove width. Thus, finally the unit cutting energy can be obtained as:

$$
E_{p}=F_{\text {total }} / A_{T}=\left(F_{t c}+F_{t f}+F_{t e}\right) / A_{T}
$$

\subsection{Specific Cutting Energy in the Brittle Regime}

In the brittle fracture regime (Figure 4), with the overall consideration of the material properties, abrasive geometry and depth of cut, the length of median cracks is given by Reference [21]:

$$
C_{m}=C_{2} \frac{(E \cdot H)^{1 / 3}}{\left(K_{c} \mu\right)^{2 / 3}}(\cot \theta)^{4 / 9}(h \cdot \tan \theta)^{4 / 3}
$$

where $C_{2}$ is a constant that equals $0.206 . K_{C}$ is the fracture toughness and $\mu$ is the material parameter determined by elastic recovery. For $\mathrm{SiC}, \mu$ is 0.34 .

Furthermore, according to the research by Arif et al. [22], the lateral cracks is proportional to median cracks, which can be obtained by:

$$
C_{l} \cong \eta C_{m}
$$

where $C_{l}$ is the lateral cracks and $\eta$ is equal to 7 [22]. Integrating the length of median cracks in Equation (16) allows us to obtain the relation of lateral crack lengths $C_{l}$ to the depth of cut $h$. In addition, based on the brittle material fracture mechanics, the fracture energy $E_{f}$ can be expressed by the function of the fracture surface and surface energy $\gamma_{\mathrm{s}}[23]$ :

$$
E_{f}=A_{s} \gamma_{s}
$$

Base on this assumption, the total fracture energy can be calculated by adding one median crack and two lateral cracks, as shown in Figure 4:

$$
E_{f}=\left(C_{l}+2 C_{m}\right) v \gamma_{s}
$$

The total deformation energy underneath the fracture stage including both plastic deformation and brittle fracture energy:

$$
\begin{gathered}
E_{b}=\left(E_{f}+E_{p}\right) / V_{b} \\
V_{b}=\frac{\pi C_{l}^{2} L}{2}
\end{gathered}
$$

in which $V_{b}$ is the removal stock by the fracture, $L$ is the scratch length per unit time, $L=v$.
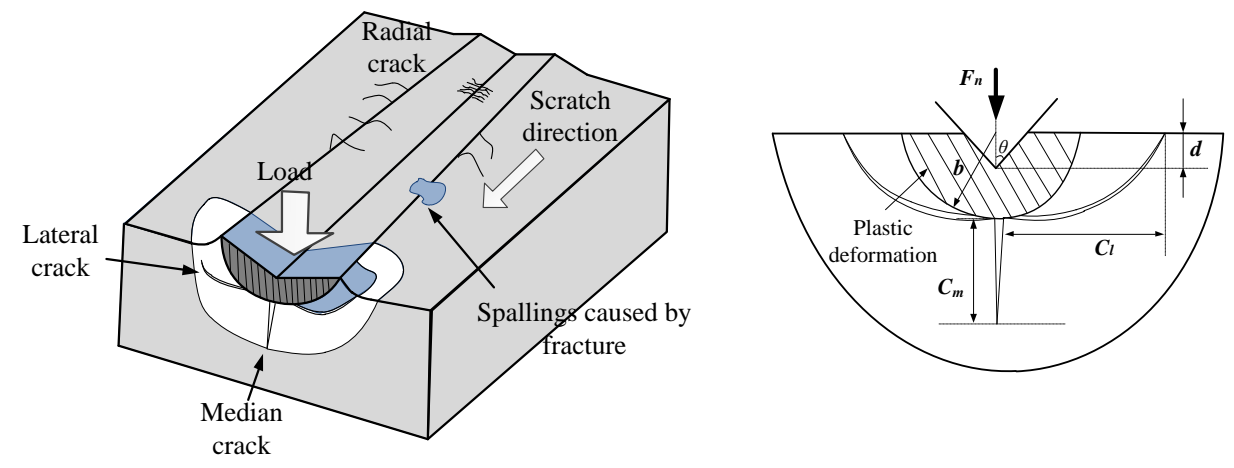

Figure 4. The schematic of scratch damage of the subsurface. 
The energies cost in the ductile and brittle regimes were analytically developed, with consideration given to the effect of strain rate caused by scratch speed. In order to predict the effect of strain rate on the critical depth of DBT and to ensure the scratch depth could cover all whole deformation stages, the scratch depth was set to 0 to $120 \mathrm{~nm}$ in the simulation. Model predictions for the effect of the strain rate on the DBT are presented in Figure 5. The interaction point of the two different specific cutting energy modes is regarded as the transition point of ductile to brittle, which means that one mode of energy transitions into the other mode. It was found that the critical depth increased with the increase in scratch velocity.

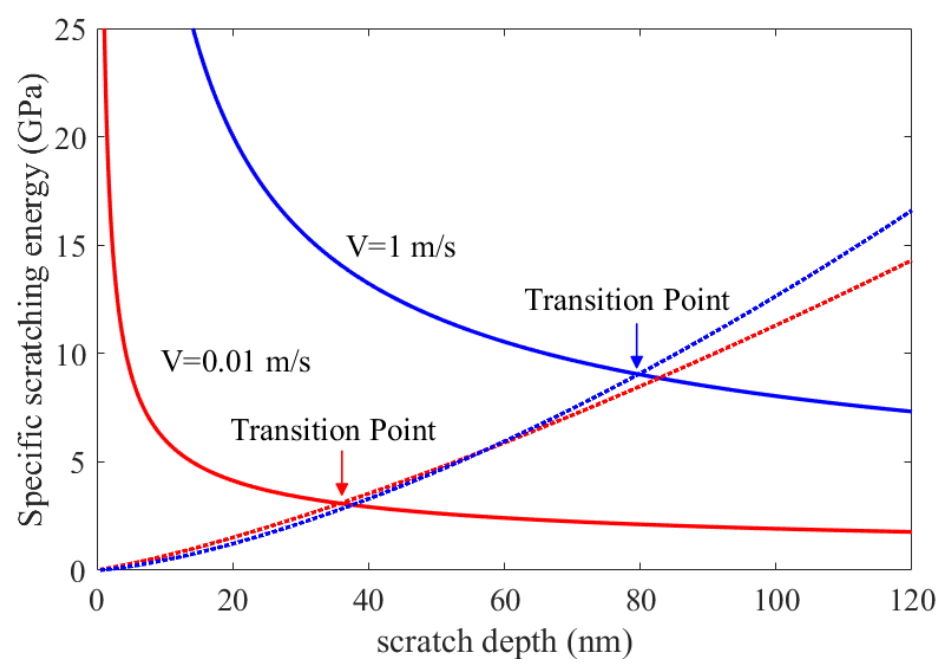

Figure 5. Predictions of various specific scratching energies with different scratch speeds in scratches on HP-SiC ceramics.

\section{Results and Discussion}

\subsection{The Residual Topography of the Scratch Groove and the Scratch Force}

Figures 6 and 7 shows the residual topography of the scratch groove under the scratch velocity of $2 \mathrm{~m} / \mathrm{s}$, and the corresponding force signal. Three distinct zones can be identified in the whole scratch process according to the emergence of cracks, i.e., the ductile mode, transitional mode and brittle mode. At the first stage when the Berkovich indenter initially cut into the material, the residual scratch groove surface had no cracks and the groove width increased steadily with the increase in scratch depth. This implies that elastic and plastic deformation dominate the machining process at such shallow scratch depths. Furthermore, the corresponding scratch force increased smoothly during this period. In the following stage when the normal force and tangential force reached 0.542 and $0.363 \mathrm{~N}$, respectively, microcracks emerged first at the bottom of the scratch groove. The scratch force exhibited obvious fluctuation as marked in Figure 7a, which suggests that the mode of machining transition into the transition phase before reaching the entirely brittle mode. As the critical depth of DBT is reached, cracks form and propagate at the sides of the scratch groove, and the corresponding force becomes unstable until the end of the scratching process. Note that the propagated lateral cracks caused the removed material to form microscopic chips. Figure 7a indicates. The occurrence of brittle-mode scratching as it becomes very unstable with continuous and remarkable fluctuations. 

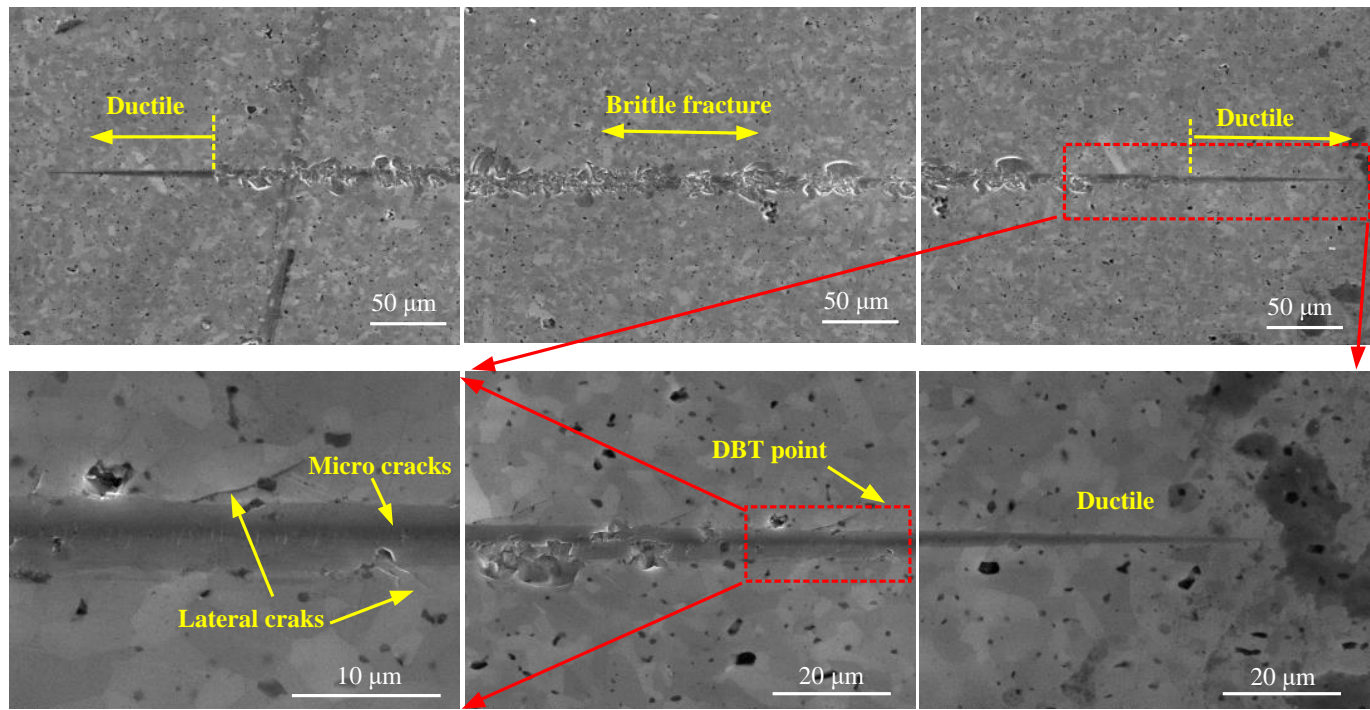

Figure 6. The scratch topography of HP-SiC ceramics with $2 \mathrm{~m} / \mathrm{s}$ scratch speed.
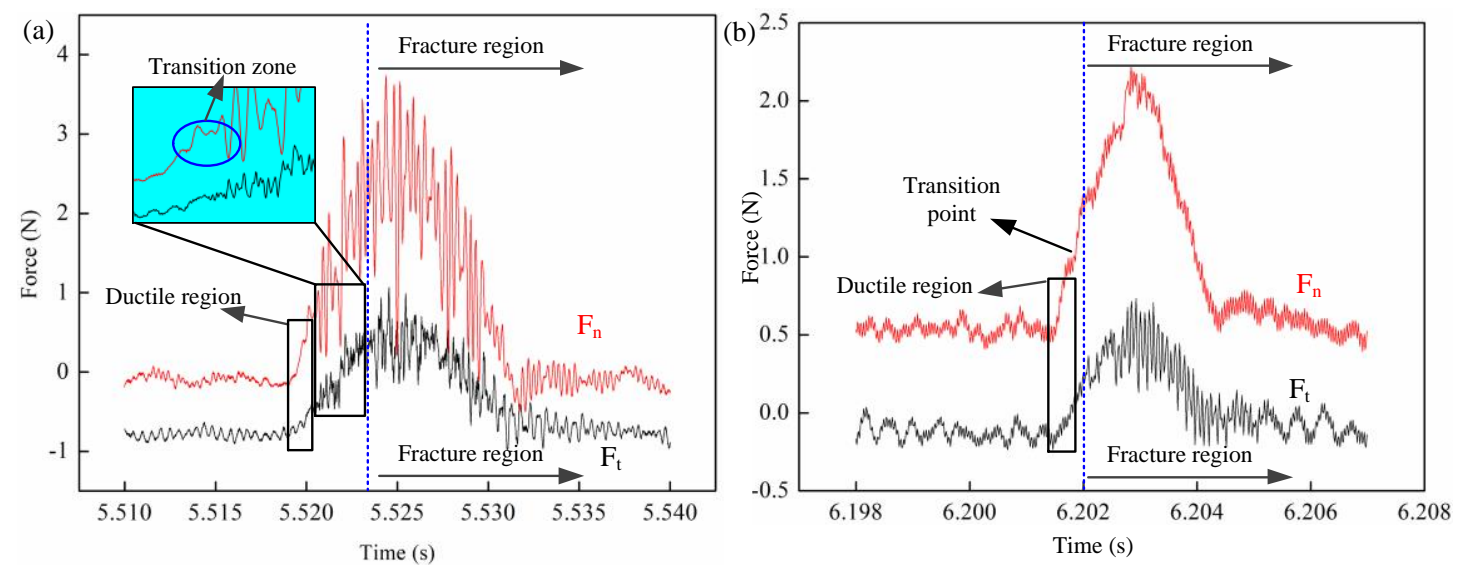

Figure 7. The measured force signal with the different scratch speeds; (a) $2 \mathrm{~m} / \mathrm{s}$; (b) $0.01 \mathrm{~m} / \mathrm{s}$.

In addition, Figure 8 shows the typical scratch topography with varied scratch speeds of $0.01 \mathrm{~m} / \mathrm{s}$, $0.3 \mathrm{~m} / \mathrm{s}, 1 \mathrm{~m} / \mathrm{s}, 2 \mathrm{~m} / \mathrm{s}$. There is no significant difference in terms of deformation regime, crack formation and propagation, apart from the length of the ductile regime. This is because the depth of DBT change was caused by the increase in the scratch (this will be discussed in detail in Section 4.3), as each scratch trajectory has the same circumference. In contrast, it was found that the tangential and normal force at the transition point were $0.35 \mathrm{~N}$ and $0.48 \mathrm{~N}$ at $0.01 \mathrm{~m} / \mathrm{s}$ scratch speed, which is much lower than $0.82 \mathrm{~N}$ and $0.56 \mathrm{~N}$ at $2 \mathrm{~m} / \mathrm{s}$ scratch speed as shown in Figure 9. This phenomenon is closely related to the material deformation mechanism. Generally, the force increases with an increase in scratch speed. This finding means that the ductile energy consumption is higher in $2 \mathrm{~m} / \mathrm{s}$ than $0.01 \mathrm{~m} / \mathrm{s}$, which indicates that the hardness of material increases due to high scratch speed, and that the stress for crack formation also increased. 


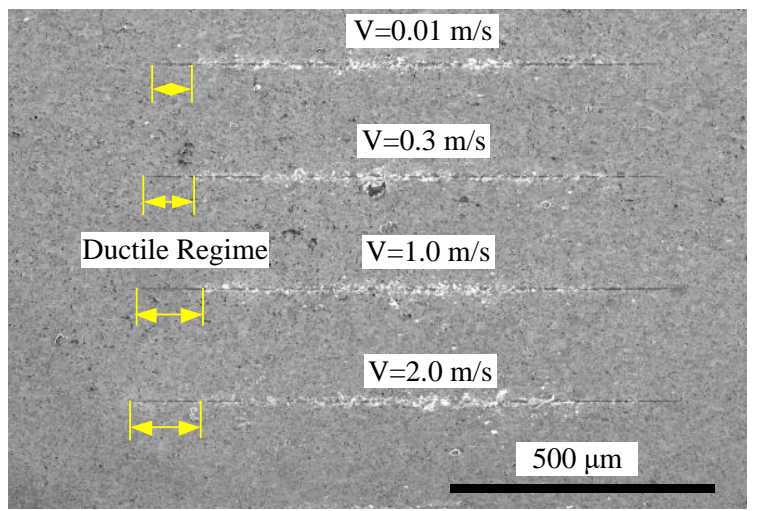

Figure 8. The residual scratch topography at different scratch speeds.

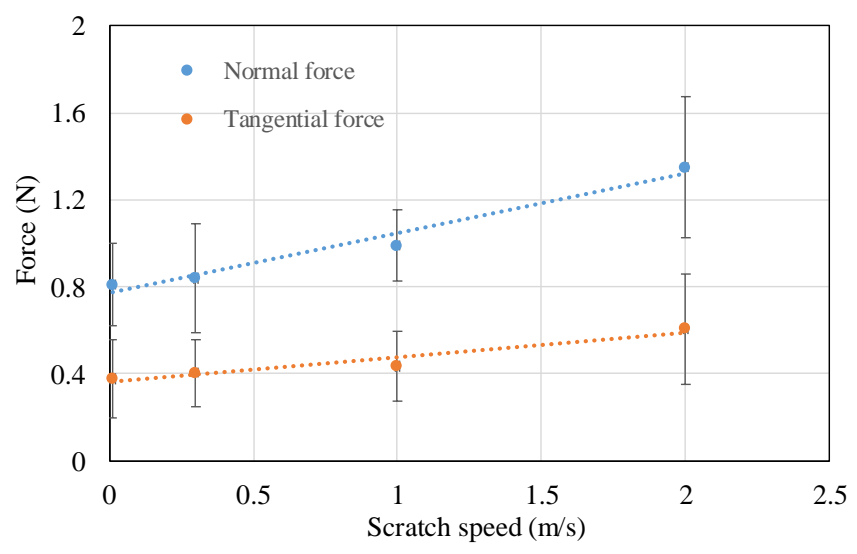

Figure 9. The measured force signal of DBT at different scratch speeds.

\subsection{Structural Analysis by Raman}

To reveal the reason for the strain rate effect on the critical depth of DBT of HP-SiC ceramics, the removal mechanism of material should be investigated in-depth. Raman spectroscopy is a powerful technique that is used to characterise the structure of SiC [24,25]. Figure 10a shows the Raman spectrum that was collected from the different positions that marked in Figure 10b,c. As a comparison, the Raman spectrum of the HP-SiC sample (Position 1) before being scratched is also exhibited. The spectra obtained before being scratched shows a series of Raman bands from 200 to $2000 \mathrm{~cm}^{-1}$ and good consistency with the spectra recorded in previously [26]. The HP-SiC is mainly composed of SiC with hexagonal close-packed (HCP) structures and residual carbides. The peaks that appear at $782.8 \mathrm{~cm}^{-1}$ and $758.5 \mathrm{~cm}^{-1}$ should be attributed to the folded modes of transverse optical (FTO) of $6 \mathrm{H}-\mathrm{SiC}$ at a reduced momentum of $x=1 / 3$ and 1 . In the high region of $900-1000 \mathrm{~cm}^{-1}$, namely the longitudinal optical (LO) phonon zone, the peaks at $944.5 \mathrm{~cm}^{-1}$ and $966.5 \mathrm{~cm}^{-1}$ should be assigned to a FLO mode of $6 \mathrm{H}-\mathrm{SiC}$ with $x=1 / 3$ and $x=0$. Furthermore, it should be noted that the weak emergences of a Si peak ( $\mathrm{Si}-\mathrm{Si}$ ) at $520 \mathrm{~cm}^{-1}$ with a broadened band implies amorphous $\mathrm{Si}$ exist in original HP-SiC ceramics [27]. As seen in Figure 10a (Position 2 to 4), it is quite clear that the scratch zone has profoundly different Raman spectra. Deformation or lattice changes of the $\mathrm{SiC}$ structure can be observed via Raman spectra. The results suggest that within the debris (Position 3) adhered along the sides of the scratch groove, amorphous transformation of $\mathrm{SiC}$ occurred, implied by the broadened band at $982 \mathrm{~cm}^{-1}$ Raman shift. Within the groove at Position 4, a broadened band at a Raman shift of $784.8 \mathrm{~cm}^{-1}$ was observed, which means that there is disordered $\mathrm{Si}-\mathrm{C}$ residual in the subsurface layer. Furthermore, it was observed that via the Raman spectra collected at Position 5, a new peak appeared at $794.5 \mathrm{~cm}^{-1}$ Raman shift. This Raman shift belongs to the $3 \mathrm{C}-\mathrm{SiC}$ or $4 \mathrm{H}-\mathrm{SiC}$, indicating stacking faults induced by the compressive stress during the scratch process $[28,29]$. The formation of stacking faults closely related 
with partial dislocations movement as a result of dissociation of a perfect dislocation during plastic deformation. It can be seen that the Raman spectra shifts to a higher frequency (from $758.5 \mathrm{~cm}^{-1}$ and $782.8 \mathrm{~cm}^{-1}$ to $762.9 \mathrm{~cm}^{-1}$ and $784.8 \mathrm{~cm}^{-1}$ ) after being scratched, which accounts for the compressive stress induced by plastic deformation of dislocations. Thus, it can be obtained that the ductile removal mechanism of HP-SiC ceramics is controlled by amorphous transformation and dislocation motion. On the other hand, it is interesting to note that the Raman spectra obtained from fracture chips (Position 2) caused by brittle fracture show no evidence of amorphous patterns, as illustrated in Figure 10a. These results indicate that the fracture chips are generated by the propagation of cracks or the cleavage of grains. The most dramatic changes are the appearance of high frequency bands, a broad band with a higher intensity in the range of 1300 to $1600 \mathrm{~cm}^{-1}$ in the chips [30]. Such Raman bands are associated with $\mathrm{C}-\mathrm{C}$ bonds, corresponding to amorphous carbon. These results indicate that impurities such as residual carbides could act as the stress concentration site which has positive effects on crack formation.
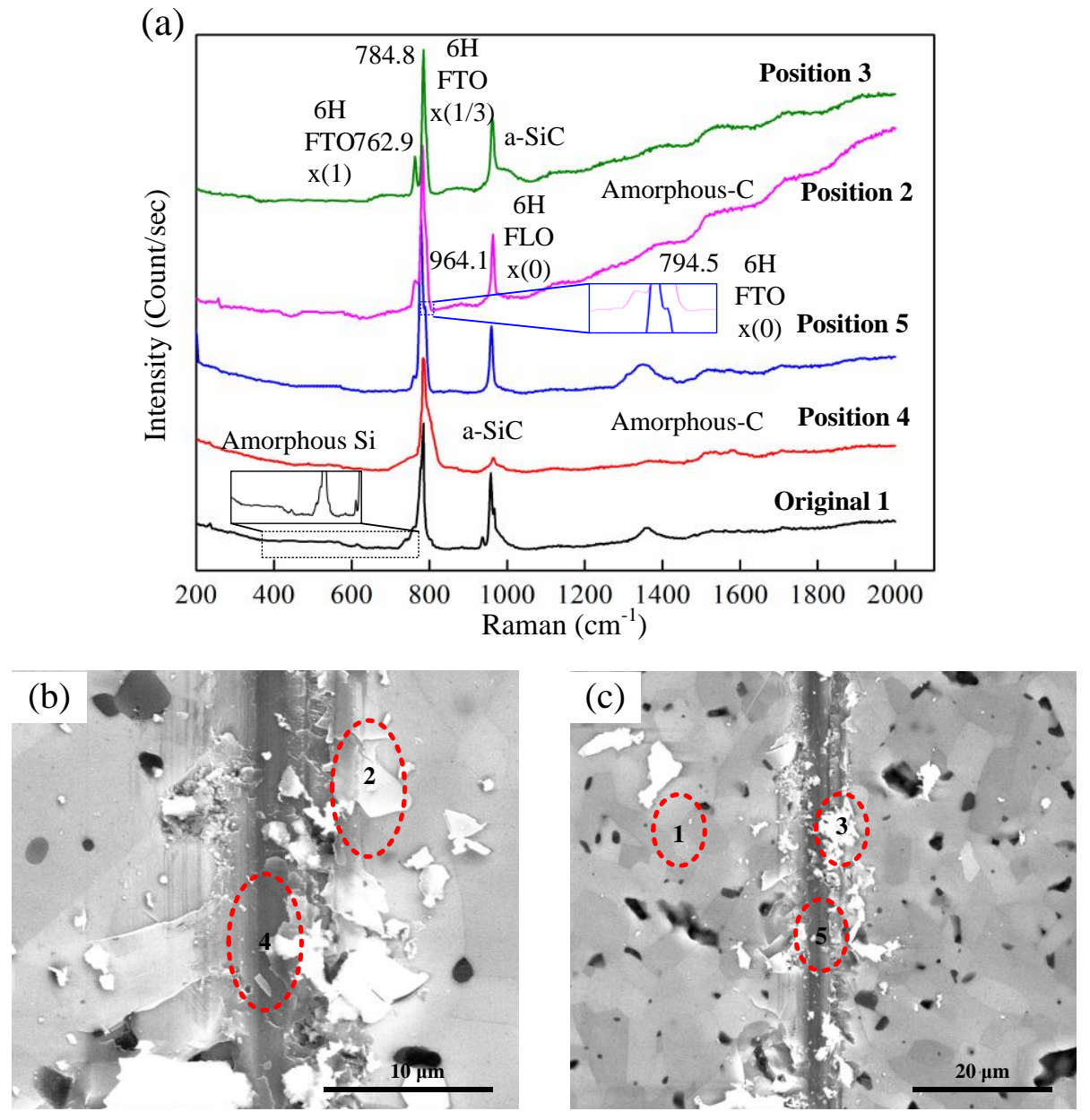

Figure 10. (a) Raman spectra collected from different positions as marked in (b) and (c); (b) and (c) Scanning electron microscope (SEM) images of topography of scratch grooves with $2 \mathrm{~m} / \mathrm{s}$ scratch speed.

\subsection{The Hardness and Young's Modulus in the Scratch}

For the measurement of thin film properties, nanoindentation experiments could provide a significant advantage over other mechanical testing methods. Therefore, this method was chosen to characterize the subsurface damage layer in micrometers. The data obtained from the nanoindentation experiments of nanohardness and Young's modulus at the cross-section of the DBT position are presented in Figure 11. The minimum value always appears at the deepest points or neighboring 
points of the scratch grooves, then gradually increased on the both sides of the center of the groove, and finally attains the value of the maximum at locations far away from the scratch grooves. The rate of change of both nanohardness and Young's modulus with the distance through the scratches were maximum at the middle of the scratch grooves and fell with a steep gradient, thereafter becoming constant at still further distances. This result indicates that the density of subsurface defects induced by scratching is higher at the center of the scratch grooves. On other hand, the data of maximum decrease in percentage of nanohardness and Young's modulus changes with different scratch speeds, as shown in Figure 12. It can be seen that nanohardness depends on the scratch speed, as its value decreased by about $45.9-18.98 \%$ when scratch speed was increased from $0.01 \mathrm{~m} / \mathrm{s}$ to $2 \mathrm{~m} / \mathrm{s}$, respectively. Similarly, the corresponding Young's modulus values decreased by about $28.85 \%$ to $12.9 \%$. This result could also explain why the depth of DBT increased with the increase in scratch speed.
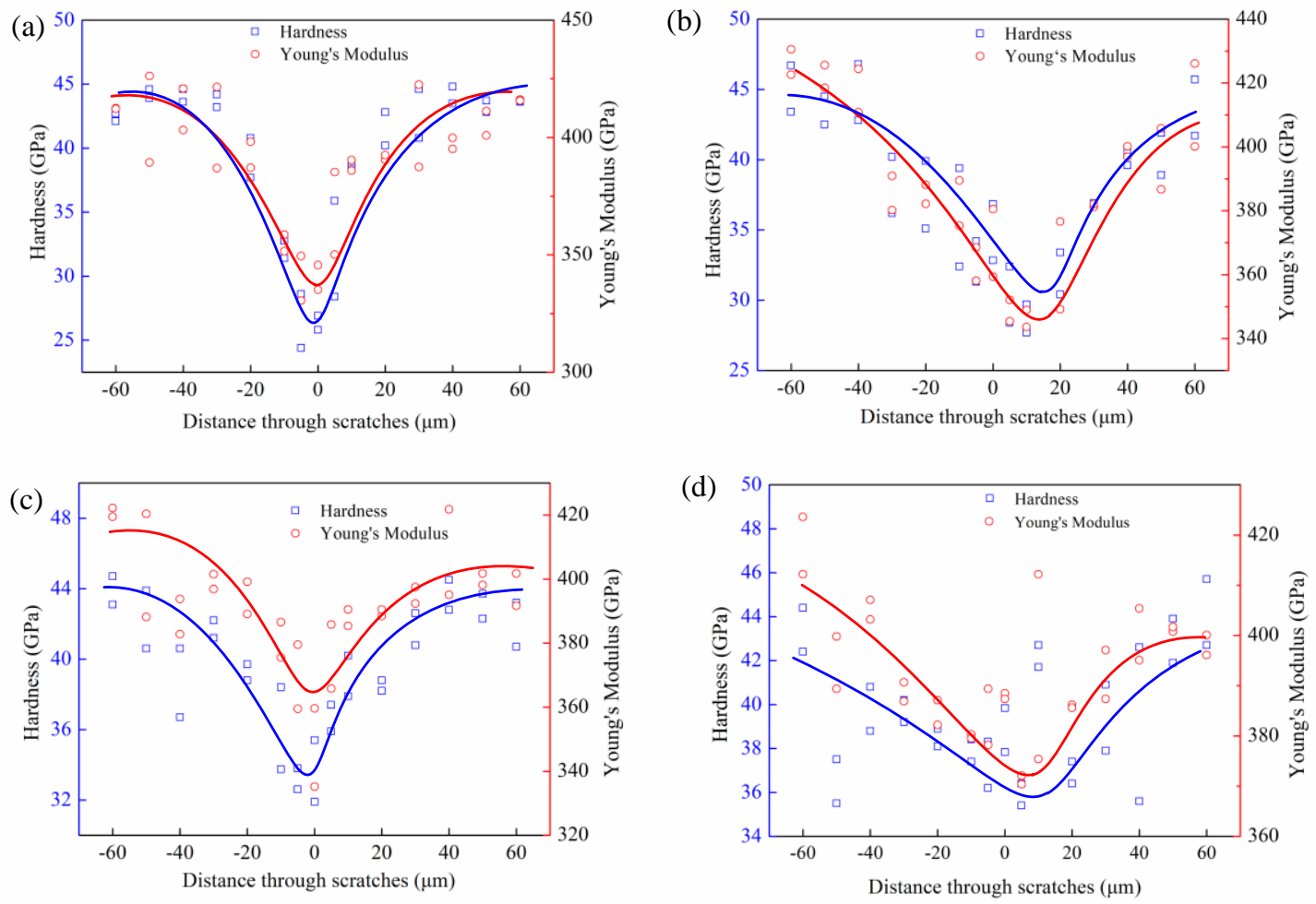

Figure 11. Plots of nanohardness and Young's modulus with distance through scratches at different scratch speeds; (a) $0.01 \mathrm{~m} / \mathrm{s}$; (b) $0.3 \mathrm{~m} / \mathrm{s}$; (c) $1 \mathrm{~m} / \mathrm{s}$; (d) $2 \mathrm{~m} / \mathrm{s}$.

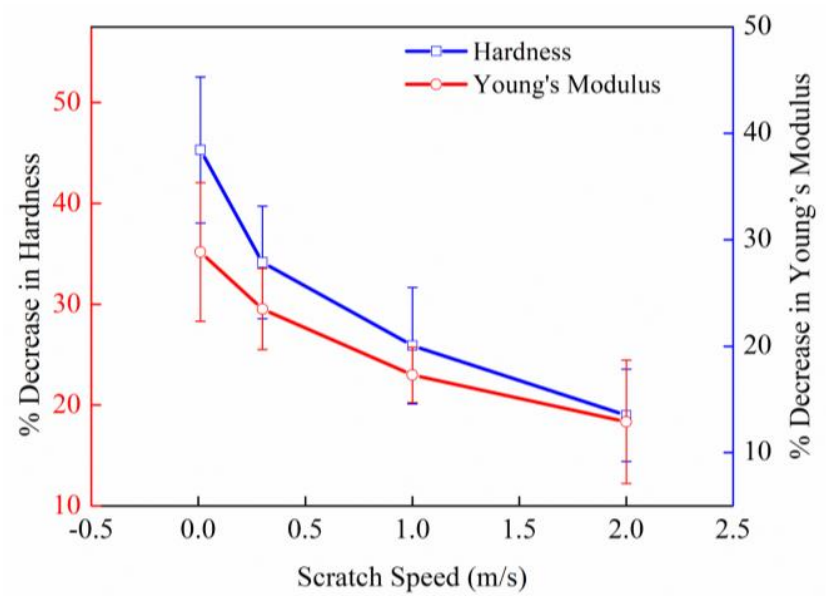

Figure 12. Percentage decrease in nanohardness and Young's modulus. 


\subsection{The Depth of DBT and Subsurface Damage}

From Raman spectra collected from beneath the scratch groove, it can be confirmed that plastic deformation of HP-SiC ceramics is governed by lattice defects (known as dislocations) and a small amount of amorphous transformation. The crystal is transported by the dislocations via bond splitting and the reforming process, and it eventually exits the grain leaving behind an atomic step in its wake. Afterwards, while the dislocations pass through each adjacent grain, the significant macroscopic strain, and hence ductility, are formed. Additionally, it is reasonable to believe that the density of dislocations and amorphous transformation are higher at high scratch speed. Afterwards, with the movement of dislocations, it will pile-up at the grain boundary and get tangled. In turn, the propagation of successive mobile dislocations is impeded. Then, the resistance of material increases, which suggests that the hardness and tensile strength increase accordingly. Consequently, the critical depth of DBT increases from $58.6 \mathrm{~nm}$ to $117.2 \mathrm{~nm}$ when scratch speed increase from $0.01 \mathrm{~m} / \mathrm{s}$ to $2 \mathrm{~m} / \mathrm{s}$, as shown in Figure 13. It can also be confirmed that the estimated value based on the predicted model has a good agreement with experimental results. It is interesting to note that the predicted value is slightly bigger than the experiment results. This phenomenon might be related to defects within the HP-SiC ceramics, such as grain boundary, the carbides phase and stacking faults, as illustrated in a previous study [31].

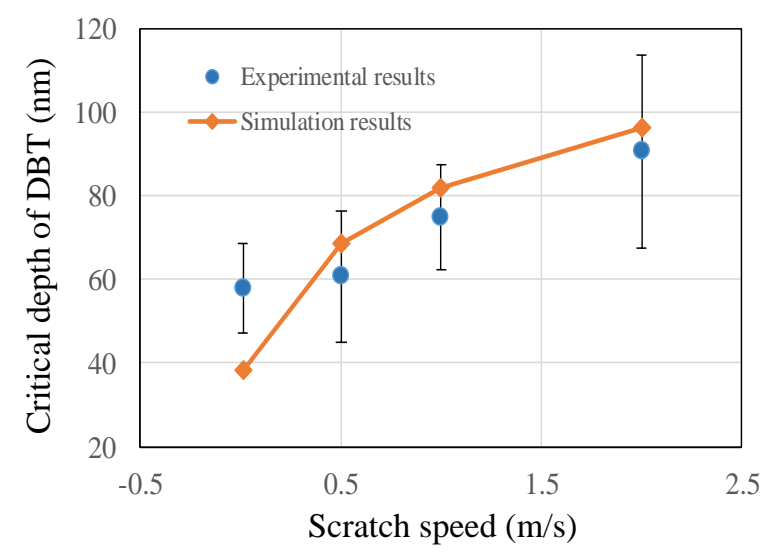

Figure 13. The critical depth of DBT obtained from experimental simulations.

Figure 14 shows the topography of the damaged subsurface at the DBT point of the scratch groove with $0.1 \mathrm{~m} / \mathrm{s}$ and $2 \mathrm{~m} / \mathrm{s}$ scratch speeds. It is obvious that higher scratch speeds lead to smaller depths of median cracks and lengths of lateral cracks. However, the crack propagation path does not conform to the regular shape and the lateral and median crack formation sites were not right underneath the contact tip between indenter and sample. This is due to the alignment of the Berkovich indenter tip and microstructural effects. This may be another reason for the error of DBT between the predicted value and experimental results. It is well known that lateral cracks occur due to residual stress when an indenter is unloaded. Thus, it can be deduced that the tensile strength HP-SiC ceramics increases with the increase in scratch speed. On the other hand, it can be observed that the extension of lateral cracks to the free surface is attributed to the material peeling, as shown in Figure 10. 

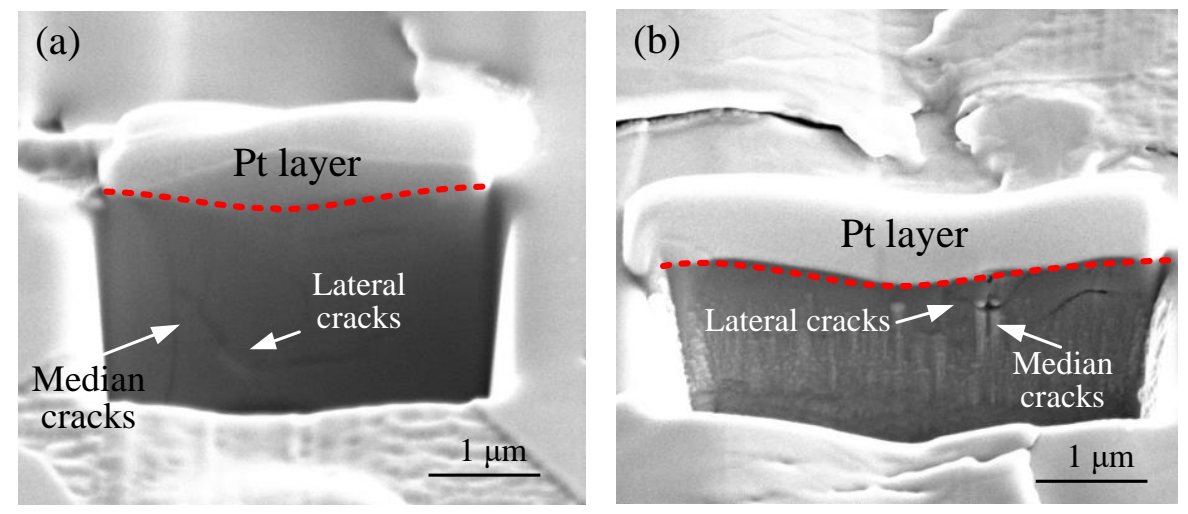

Figure 14. SEM images of subsurface damage (a) $0.01 \mathrm{~m} / \mathrm{s},(\mathbf{b}) 2 \mathrm{~m} / \mathrm{s}$.

\section{Conclusions}

The micro cracks and fractures are always inevitably induced in the machining of HP-SiC ceramics. The critical depth of DBT is closely related with material properties, machining conditions and complex removal mechanisms of both the ductile and brittle mode. Therefore, this paper developed a prediction model about critical depth of DBT based on the specific cutting energies consumed in the ductile and brittle modes. The effect of strain rate caused by scratch speed was taken into consideration. Then, single-grit grinding experiments were performed to verify the reliability of the model. To explore the reason for the effect of scratch speed on DBT of HP-SiC ceramics, material removal mechanisms were investigated using Raman. The following conclusions can be drawn according to the experiments and theoretical analysis:

(1) The removal characterizes of HP-SiC ceramics in a single-grit grinding process can be distinguished into three areas, i.e., ductile, DBT and fracture. A theoretical model incorporating the strain rate was developed to evaluate the scratch-induced damages.

(2) Scratch speed-dependent strain rate has an obvious effect on the critical depth of DBT of $\mathrm{HP}-\mathrm{SiC}$ ceramics. An increase in scratch speed leads to a higher hardness, higher Young's modulus and higher critical depth of DBT. The simulation value based on the proposed model agreed well with the experiments results.

(3) The ductile removal mechanism of HP-SiC ceramics is dominated by phase transformation and dislocation motions. The pile-up and tangling of dislocations decide the DBT of HP-SiC ceramics in a high strain rate.

(4) A higher scratch speed can reduce the subsurface damage depth at the DBT of HP-SiC ceramics, which suggests that a high grinding speed could inhibit the subsurface damage of HP-SiC ceramics.

Author Contributions: P.H.: experimental analysis, processing of the results and writing; J.Z.: conceptualization, writing-reviewing and editing and project administration-reviewing and editing. All authors have read and agreed to the published version of the manuscript.

Funding: This research was funded by the Science and Technology Foundation of Department of Education, Jilin Province (Grant: JJKH20190136KJ) and the Open Foundation of State Key Laboratory of Inorganic Synthesis and Preparative Chemistry, Jilin University (Grant: 2019-24).

Conflicts of Interest: The authors declare no conflict of interest.

\section{References}

1. Xie, J.; Li, Q.; Sun, J.; Li, Y. Study on ductile-mode mirror grinding of SiC ceramic freeform surface using an elliptical torus-shaped diamond wheel. J. Mater. Process. Technol. 2015, 222, 422-433. [CrossRef]

2. Wu, C.; Pang, J.; Li, B.; Liang, S.Y. High-speed grinding of HIP-SiC ceramics on transformation of microscopic features. Int. J. Adv. Manuf. Technol. 2019, 102, 1913-1921. [CrossRef]

3. Agarwal, S.; Rao, P.V. Experimental investigation of surface/subsurface damage formation and material removal mechanisms in SiC grinding. Int. J. Mach. Tools Manuf. 2008, 48, 698-710. [CrossRef] 
4. Zeller, F.; Müller, C.; Miranzo, P.; Belmonte, M. Exceptional micromachining performance of silicon carbide ceramics by adding graphene nanoplatelets. J. Eur. Ceram. Soc. 2017, 37, 3813-3821. [CrossRef]

5. Liu, L.; Zhang, F. Prediction model of form error influenced by grinding wheel wear in grinding process of large-scale aspheric surface with SiC ceramics. Int. J. Adv. Manuf. Technol. 2016, 88, 899-906. [CrossRef]

6. Feng, G.; Guo, J.; Zhang, G. Material removal characteristics of ultra-precision grinding silicon carbide ceramics. Adv. Appl. Ceram. 2019, 119, 175-182. [CrossRef]

7. Cao, J.; Wu, Y.; Lu, N.; Fujimoto, M.; Nomura, M. Material removal behavior in ultrasonic-assisted scratching of $\mathrm{SiC}$ ceramics with a single diamond tool. Int. J. Mach. Tools Manuf. 2014, 79, 49-61. [CrossRef]

8. Zhu, D.; Yan, S.; Li, B. Single-grit modeling and simulation of crack initiation and propagation in SiC grinding using maximum undeformed chip thickness. Comput. Mater. Sci. 2014, 92, 13-21. [CrossRef]

9. Xie, Z.-H.; Hoffman, M.; Moon, R.J.; Munroe, P.R.; Cheng, Y.-B. Scratch damage in ceramics: Role of microstructure. J. Am. Ceram. Soc. 2003, 86, 141-148. [CrossRef]

10. Subhash, G.; Bandyo, R. A new scratch resistance measure for structural ceramics. J. Am. Ceram. Soc. 2005, 88, 918-925. [CrossRef]

11. Qiu, Z.; Liu, C.; Wang, H.; Yang, X.; Fang, F.; Tang, J. Crack propagation and the material removal mechanism of glass-ceramics by the scratch test. J. Mech. Behav. Biomed. Mater. 2016, 64, 75-85. [CrossRef]

12. Meng, B.; Zhang, Y.; Zhang, F. Material removal mechanism of $6 \mathrm{H}-\mathrm{SiC}$ studied by nano-scratching with Berkovich indenter. Appl. Phys. A 2016, 122, 247. [CrossRef]

13. Li, Z.; Zhang, F.; Luo, X.; Cai, Y. Fundamental understanding of the deformation mechanism and corresponding behavior of RB-SiC ceramics subjected to nano-scratch in ambient temperature. Appl. Surf. Sci. 2019, 469, 674-683. [CrossRef]

14. Li, Z.; Zhang, F.; Zhang, Y.; Luo, X. Experimental investigation on the surface and subsurface damages characteristics and formation mechanisms in ultra-precision grinding of SiC. Int. J. Adv. Manuf. Technol. 2017, 92, 2677-2688. [CrossRef]

15. Xiao, G.; To, S.; Zhang, G. The mechanism of ductile deformation in ductile regime machining of $6 \mathrm{H} \mathrm{SiC}$. Comput. Mater. Sci. 2015, 98, 178-188. [CrossRef]

16. Bowden, F.P. The Friction and lubrication of solids. Am. J. Phys. 1951, 19, 428. [CrossRef]

17. Pirouz, P.; Zhang, M.; Demenet, J.-L.; Hobgood, H.M. Transition from brittleness to ductility in SiC. J. Phys. Condens. Matter 2002, 14, 12929-12945. [CrossRef]

18. Rabier, J.; George, A. Dislocations and plasticity in semiconductors. II. The relation between dislocation dynamics and plastic deformation. Rev. Phys. Appl. 1987, 22, 1327-1351. [CrossRef]

19. Grau, P.; Berg, G.; Meinhard, H.; Mosch, S. Strain rate dependence of the hardness of glass and Meyer's law. J. Am. Ceram. Soc. 2005, 81, 1557-1564. [CrossRef]

20. Arcona, C.; Dow, T.A. An empirical tool force model for precision machining. J. Manuf. Sci. Eng. 1998, 120, 700-707. [CrossRef]

21. Gu, W.; Yao, Z.; Li, K. Evaluation of subsurface crack depth during scratch test for optical glass BK7. Proc. Inst. Mech. Eng. Part C J. Mech. Eng. Sci. 2011, 225, 2767-2774. [CrossRef]

22. Arif, M.; Rahman, M.; San, W.Y. Analytical model to determine the critical feed peredge for ductile-brittle transition in milling process of brittle materials. Int. J. Mach. Tool Manuf. 2011, 51, 170-181. [CrossRef]

23. Coppola, J.A.; Bradt, R.C. Measurement of fracture surface energy of SiC. J. Am. Ceram. Soc. 1972, 55, 455-460. [CrossRef]

24. Nakashima, S.; Harima, H. Raman investigation of SiC polytypes. Phys. Status Solidi A 1997, 162, 39-64. [CrossRef]

25. Nakashima, S.-I.; Mitani, T.; Tomobe, M.; Kato, T.; Okumura, H. Raman characterization of damaged layers of $4 \mathrm{H}-\mathrm{SiC}$ induced by scratching. AIP Adv. 2016, 6, 15207. [CrossRef]

26. Su, B.; Liang, H.; Liu, G.; Yu, D.Y.W.; Huang, Z.; Liu, X.; Chen, Z. Damage development of sintered SiC ceramics with the depth variation in Ar ion-irradiation at $600{ }^{\circ}$ C. J. Eur. Ceram. Soc. 2018, 38, 2289-2296. [CrossRef]

27. Jasinevicius, R.G.; Duduch, J.G.; Pizani, P.S. In-situ raman spectroscopy analysis of re-crystallization annealing of diamond turned silicon crystal. J. Braz. Soc. Mech. Sci. Eng. 2007, 29, 49-54. [CrossRef]

28. Scuderi, V.; Calabretta, C.; Anzalone, R.; Mauceri, M.; La Via, F. Characterization of 4H- and 6H-like stacking faults in cross section of 3C-SiC epitaxial layer by room-temperature $\mu$-photoluminescence and $\mu$-raman analysis. Materials 2020, 13, 1837. [CrossRef] [PubMed] 
29. Boutopoulos, C.; Terzis, P.; Zergioti, I.; Kontos, A.; Zekentes, K.; Giannakopoulos, K.; Raptis, Y. Laser annealing of $\mathrm{Al}$ implanted silicon carbide: Structural and optical characterization. Appl. Surf. Sci. 2007, 253, 7912-7916. [CrossRef]

30. Jorio, A.; Souza Filho, A.G. Raman Studies of Carbon Nanostructures. Annu. Rev. Mater. Res. 2016, 46, 357-382. [CrossRef]

31. Hogan, J.D.; Farbaniec, L.; Sano, T.; Shaeffer, M.; Ramesh, K.T. The effects of defects on the uniaxial compressive strength and failure of an advanced ceramic. ACTA Mater. 2016, 102, 263-272. [CrossRef]

(C) 2020 by the authors. Licensee MDPI, Basel, Switzerland. This article is an open access article distributed under the terms and conditions of the Creative Commons Attribution (CC BY) license (http://creativecommons.org/licenses/by/4.0/). 